\title{
Child Sexual Abuse and Exploitation: Knowledge, Confidence and Training within a Contemporary UK Social Work Practice and Policy Context
}

\author{
Josephine Kwhali, Linda Martin, Geraldine Brady* and \\ Sarah J. Brown
}

Faculty of Health and Life Sciences, Coventry University, Coventry, CV1 5FB, UK

*Correspondence to Dr Geraldine Brady, Reader in Sociology of Childhood and Youth, Faculty of Health and Life Science, Coventry University, Priory Street, Coventry, CV1 5FB, UK. E-mail: G.Brady@coventry.ac.uk

\begin{abstract}
In 2014, research was undertaken to examine social workers' confidence, understanding and awareness of child sexual abuse (CSA) as it was suggested that a decline in numbers of reported incidents might be due to a decline in levels of understanding and awareness. Semi-structured interviews were conducted with twenty-five first-line, middle and senior managers and two chairs of local safeguarding boards across six local authorities in England. Focus groups were conducted with fifty-four social workers. Key themes revealed a complex array of issues, ranging from the diverse forms of CSA and exploitation that social workers are required to address, the variable support and training available, and the inter-disciplinary nature of much of the work. Although social workers undertake this important work with a strong sense of commitment and concern for children, they face a number of challenges. Paradoxically, whilst their work on these cases is the source of intense scrutiny, the training, support and supervision, and role clarity required to undertake this work well are often overlooked. The aim of this paper is to discuss the research findings and to identify implications for social work practice, training, multi-agency work and future research.
\end{abstract}

Keywords: CSA, CSE, critical reflection, education, social work, training

Accepted: September 2016 


\section{Introduction}

In March 2015, former British Prime Minister David Cameron stated that child sexual abuse (CSA) was a 'national threat' and responding to it a national priority. CSA occurs when a child is 'forced or persuaded to take part in sexual activities. This doesn't have to be physical contact and it can happen online' (NSPCC, 2016). The definition of child sexual exploitation (CSE), which is a form of CSA, was recently defined by UK's Department for Education (Department for Education and Home Office, 2016) as when a child or young person under the age of eighteen is 'persuaded, coerced or forced into sexual activity in exchange for, amongst other things, money, drugs/alcohol, gifts, affection or status'. Social workers in England are at the forefront of the response to CSA and CSE (CSA/E) and have important responsibilities for safeguarding children and invoking child protection policies.

Despite the spotlight on $\mathrm{CSA} / \mathrm{E}$, child protection registration figures and the number of children being made subject of child protection plans for sexual abuse was lower than it was a decade ago and significantly lower than two decades ago (Brown et al., 2011). Questions were raised about the reasons for this decline, particularly since it contrasted with an increase in reported incidents of CSA/E (NSPCC, 2015) and professional practice had been challenged following reports of failures in responding to CSA/E allegations (e.g. Jay, 2014). NSPCC scoping work suggested that the reduction in reported incidents might be due to professionals' decline in levels of understanding and awareness. Rapid developments in practice, particularly in relation to CSE, and a shift from family support to child protection (Featherstone et al., 2013) made it difficult for professionals to keep abreast of changes.

It was against this backdrop that research was commissioned by the NSPCC to explore social workers' confidence and understanding of CSA. The research report is available on the NSPCC website (Martin et al., 2014) and, in this paper, our focus is on the implications arising from it. After outlining the method, we discuss in turn, noting the findings and implications, two of the core themes from the research findings: practice issues in relation to social workers' knowledge and confidence; and effective support, supervision and training. Finally, we identify the implications for $\mathrm{CSA} / \mathrm{E}$ practice, education, training and multi-agency work that arose from the research.

\section{Method}

Ethical approval was gained from the authors' university and the Association of Directors of Children's Services (England) Research Group. An advisory group of experienced professionals was established 
to guide the research. Seven of the forty-five English local authorities (LAs) invited to participate in the study agreed, and six were able to participate within the time frame. The size and nature of these varied, with three located in the East and West Midlands, one in London, one in East Anglia and one in the North-West. Four had nationally 'low' and two 'medium' rates of reported cases of CSA (see Martin et al. (2014) for more details about the method and participating authorities). In each LA, two focus groups were held: one with Safeguarding Teams and one with Duty and Assessment, Child in Need and/or Looked After teams. In addition, a team manager and middle manager with responsibility for safeguarding practice, the relevant senior manager and, where possible, the Chair of the Local Safeguarding Children's Board (LSCB) were interviewed. Semi-structured interviews were conducted with twenty-five first-line, middle and senior managers and two chairs of LSCBs; twelve focus groups with a total of fifty-four social workers were facilitated. All were digitally recorded and transcribed verbatim. Participants varied in terms of level of social work experience and, where possible, diverse social and ethnic backgrounds were represented. There were two experienced social workers on the research team, one of whom had held Head of Children's Services roles. Their familiarity with the pressures and challenges experienced by front line social workers were to prove invaluable whilst collecting data in the field, balancing the sensitivity of encouraging staff and managers to talk about their knowledge and confidence (or lack of) yet recognising when practice was unsafe and needed improvement. The focus group and interview transcripts were analysed using framework analysis (Richie and Lewis, 2003); initial emerging themes were used to develop a thematic framework that helped to illuminate similarities and differences between participants and LAs. To ensure confidentiality, the names of participating LAs and individuals are not identified; data extracts are attributed by LA and focus group number (e.g. LA1, FG2). Each LA was provided with a summary of key findings respective to the authority, including where participants had indicated need for improvement in practice and training.

\section{Findings, discussion and implications for practice}

This section is organised around two of the core themes that emerged from the research: 'Practice issues, knowledge and confidence' and 'Effective support, supervision and training' (Martin et al., 2014). Each subsection will consider the main findings without seeking to repeat the original report, before discussing the implications for CSA/E practice. 


\section{Main findings: practice issues, knowledge and confidence}

The purpose of undertaking focus groups and interviews was to establish how confident and self-assured social workers and managers felt in relation to working with $\mathrm{CSA} / \mathrm{E}$. Questions explored training and career pathways into their current field of work, current role and details of memorandum, post-qualifying and multidisciplinary training in the field of child safeguarding. We also focused on experience of working in social work with children and families generally and with specific reference to $\mathrm{CSA} / \mathrm{E}$ including the nature, range and scale of their experience.

Some participants considered themselves to have considerable experience and knowledge of CSA work, while others were less experienced and more cautious in their assertions. Social workers' experience of CSA was primarily acquired through the assessment or management of cases where sexual abuse was perpetrated by a family member or associate. Procedures and guidance were well developed in this area and there were usually other staff members or managers whom they could turn to for advice. Participants recognised that incidents of CSA could emerge through the identification of other categories of harm, through working directly with children in foster-care, adoption and leaving care services or through the assessment of a child initially referred for family support. Social workers in our research reinforced the need for all practitioners to have understanding of $\mathrm{CSA} / \mathrm{E}$ and to build up their expertise and knowledge. Whilst the management of $\mathrm{CSA} / \mathrm{E}$ cases was viewed as stressful and complex, it was considered a core component of social workers' safeguarding responsibilities. In general, social workers considered themselves confident in discussing and managing familial CSA, whilst also reporting that confidence was undermined by staff shortages and high caseloads.

Participants stressed that direct work in cases of CSA needs preparation and time for reflection-'it's not something you just go and do' and this space was rarely available. For example, one social worker (LA2, FG1) indicated that insufficient time was allocated to build trusting relationships with children in a family where sibling abuse had taken place, so she visited at the end of the day to ensure her manager was unaware of the additional hours being spent. Fine and Teram (2013) perceive that the organisational climate can be such that social workers feel the need to respond by masking and smoothing institutional inadequacies. They argue that, whilst this may be a way of supporting individual families, acting overtly to address perceived social injustice is more likely to lead to institutional change.

Social workers gave examples of cases being closed either because the child or alleged abuser had been removed from the abusive situation or as a result of more pressing referrals. This left the child and other family 
members vulnerable at a point when the investigating agencies withdrew. One social worker warned 'you can forget there's a child in the middle of it' (LA5, FG2) and another said 'it isn't all about a Police investigation, it's about them' (LA2, FG2). Social workers in four authorities (1, 3, 4 and 5) raised specific concerns when the police were undertaking investigations and the lack of clarity as to their own role in supporting children and other family members. They also expressed concern about potential delays in children accessing therapeutic intervention. Also, "stalling" for so long and telling them that they've done the right thing but actually we're going to do nothing about it for a bit'(LA5, FG1) whilst criminal investigations were concluded potentially made it worse for a child if left unsupported to deal with the aftermath of sexual abuse disclosure. A social worker spoke of her distress of working with a young girl (age not specified) who had been raped and the trauma for the girl in undergoing medical and criminal procedures, commenting 'And it's left with you to sort of hold it, it's all left on you' (LA3, FG1).

Less confidence was shown by research participants when cases involved grooming, trafficking, internet abuse and other types of exploitative behaviour and where multi-agency responses were required. Few research participants had direct experience of working with trafficked or groomed children. They consistently expressed uncertainty as to their role in partnership working and how the social work function might best be exercised in assessing and supporting children and young people subject to CSE. Confidence was further eroded by the allocation of cases based on numerical capacity or availability of staff, rather than levels of expertise or prior experience.

The uncertainty regarding the social work role was also evident in social workers' and managers' discussions of the Multi Agency Safeguarding Hubs (MASH) that were incrementally developed following the Munro review (2011) of child protection. Established to improve information sharing and decision making between agencies when cases of potential child exploitation were referred or identified, social workers in one authority (LA2) knew little about the newly established MASH team, commenting that it dealt mainly with cases of grooming and CSE. When asked whether such children and young people were then referred under section 47 and made subject to child protection plans, the social workers indicated otherwise, suggesting that such cases were matters for the police.

Management participants, including team managers and those working at a strategic level, expressed some uncertainty about the interrelationship between MASH and child protection services. They felt there was a lack of clarity between the MASH and the recording and management of CSE cases and those of familial abuse managed within children's social work. This leads to concerns as to the potential under-recording of 
CSA and the low prioritisation of therapeutic support that might be given to children and young people who have been groomed and sexually exploited.

Throughout the research, concern was expressed by both managers and social workers about the reliance on the voluntary sector for direct post-disclosure therapeutic work with sexually abused children. Social workers were concerned with the sustainability of the service, not necessarily the quality of provision. Lengthy waiting times and the limited availability of appropriate services, particularly for teenagers, young people from minority ethnic groups and children with disabilities, was a disturbing reality—-findings also observed by Allnock et al. (2012).

\section{Discussion and implications of the findings}

\section{The importance of skilled intervention}

Where timely and skilled intervention exists, research suggests that it can make a positive contribution to both sexually abused children and their carers. For example, Carpenter and Hackett (2016) carried out an independent study of an NSPCC service for children who had been sexually abused and who were now living with non-abusing parents. The majority of staff who delivered the programme ( 89 per cent) were qualified and experienced social workers who had the opportunity to develop long-term therapeutic relationships with children and parents. A positive impact of the programme was demonstrated for children who received it immediately after assessment in comparison to the group who waited for six months and this was particularly evident in older children.

The role of the NSPCC social workers delivering this programme differed markedly from the social workers interviewed during our research working within LA children's safeguarding teams. The dominant theme was the limited time available to support the young person once the assessment of risk had been completed and the child's immediate welfare safeguarded. This was despite social workers wanting to undertake direct work with children and recognising the necessity for it. Ferguson (2011, p. 37) critiqued the manner in which 'more and more laws, procedures and guidance' had been introduced in response to safeguarding failures, citing their impact on the erosion of social work practice skills and faceto-face work with children and their families. This observation was reinforced by social workers in our research, who noted the centrality of paperwork and the child protection process with little opportunity to undertake long-term work or to advocate for the support that a child and her/his family might need. This raises important policy issues as to why statutory social work services are not resourced to undertake longterm therapeutic work. 
The relationship between criminal conviction and social work intervention

The Butler-Sloss report (1988) into the sexual abuse of children in Cleveland identified the need for all agencies involved in the protection of children to work together. In 2002, the Department of Health published a report from findings of individual and joint inspections of English authorities carried out by eight inspectorates. The inspectorates identified that, whilst public agencies were aware of their joint responsibilities to work together in the protection and safeguarding of children, this was not always reflected in practice, with variable funding arrangements for Area Children Protection Committees (which preceded LSCBs) and inter-agency management involvement in them. The findings were given increased impetus by Lord Laming's report (2003) into the death of Victoria Climbié in 2000. The 2004 Children Act placed inter-agency planning and collaboration on a statutory level through the establishment of LSCBs. Government guidance on safeguarding children from CSE (Department of Children, Schools and Families, 2009) endowed the boards with the responsibility to work on an inter-agency basis both to protect the child and prosecute the abuser. Working Together to Safeguard Children identified the lead role of LAs, whilst reiterating the principle that 'safeguarding is everyone's responsibility: for services to be effective each professional and organisation should play their full part' (HM Government, 2015, p. 8).

Despite the LA's lead role in child protection being enshrined in legislation, Hughes and Owen (2009, p. 13) cites Laming's (2003) recommendation (p. 97) that a 'crime against a child should be treated just as seriously as a crime against an adult and that the police should very much take the lead in investigating and prosecuting child abuse offences'. She suggested that this 'led to a loss of impetus in the social work role in investigation developed since the Cleveland Inquiry (Butler-Sloss, 1988) and a deterioration in joint close working between police and social workers' (Hughes and Owen, 2009, p. 13).

Our research reaffirmed social workers' views that conviction can provide validation to a child, so its pursuit may be essential both to the prevention of abuse and the well-being of the child. The importance of a successful prosecution for the recovery of some children and young people who have experienced abuse is recognised but it is the dynamic of the relationship between prosecution and protection that may pose a threat to the long-term well-being of the child. Additionally, Beckett and Warrington (2015, p. 3) identified the manner in which engagement with the criminal process can be disempowering for victims of CSE, with one young person indicating 'that the court process was worse than the exploitation itself'. 
Central to the potential conflict between 'investigation and prosecution' and 'investigation and child welfare support' was the practice in some of the participating LAs to postpone social work or therapeutic intervention until criminal proceedings had been completed-a practice sometimes requested by the police in order to avoid the potential contamination of evidence. Important questions were then raised as to how the LA then works in partnership with the non-abusing parent and other family members (1989 Children Act, section 1) and to centre the emotional well-being of the child. The paramouncy principle has been intrinsic to child-care practice since the implementation of the 1989 Children Act and reinforced through subsequent legislation, guidance and child protection inquiry reports (Laming, 2003; Munro, 2011). Despite this, in a report for the Office for Children's Commissioner's (OCC), Horvath et al. (2014, p. 16) concluded that 'it is clear...that the child protection system has become overly bureaucratic and target-centred. This is at the expense of forming good relationships with, listening to, and ultimately protecting, children'.

The child welfare principle is further undermined if the social work safeguarding role is primarily restricted to single agency investigations of sexual (and other) forms of abuse, with the police and medical personnel determining when and if social workers can intervene where a crime is suspected. This raises important issues as to the core purpose of social work, how the expertise of qualified social workers should best be used and the status of the profession in the multi-agency context. Social workers need to be able to enter inter-professional negotiations on an equal footing but 'role slumping' (the practice of higher-level managers intervening in decisions that should be made at practitioner level) (Katz and Kahn, 1978; Searle and Patent, 2013) potentially undermines their ability to do this effectively.

A response to the process of disclosure cannot be formulaic or undermining of child-focused social work practice, but must recognise the short- and longer-term support that a child might require (Beckett, 2007). Anxiety associated with talking to the police and giving evidence in court alongside a lack of information may compound the impact of the abuse resulting in increased distress for the child (Back et al., 2011; Beckett and Warrington, 2015). Hence, an approach that entails a childcentred response agreed by both social workers and the police, which necessitates discussion regarding the management of the prosecution and support dimensions for every child, is required, with no existing parameters or preconceptions about the prosecution and protection relationship. The achievement of this may hinge on the equality of the working relationship between agencies and the ability of managers to challenge a predestined ordering of activities. Challenges to achieving this have been highlighted previously, such as the primacy given to the evidence for prosecution, the police assuming a lead role and social 
workers lacking confidence in their own skills and knowledge (Garrett, 2004; Westwood, 2012). Social workers in our research indicated that these are still real issues that need to be addressed if the situation is to change.

\section{Multi-agency safeguarding hubs}

MASHs were developed to assist in multi-agency information sharing. Reviews have been largely positive (Crockett et al., 2013; Chilvers, 2013; Home Office, 2014; Centre of Excellence for Information Sharing, 2014), noting an enhanced understanding of the different professional roles and inter-agency discussion as to what should happen in a case. MASH personnel are not involved in subsequent single or joint section 47 investigations, meaning that experienced social workers could be drawn away from direct practice. More concerning, and as identified in our study, social workers may come to see MASH teams as operationally apart from other parts of the safeguarding arrangements, dealing primarily with cases of CSE. As the sexual abuse of children and young people takes different forms (familial, trafficking, peer to peer, networks, online, etc.) and could be categorised as CSA or CSE, concerns were raised by social workers when there appeared to be ambiguity in the way disclosures were captured and categorised, leading to either a police-led response or a safeguarding response. Confusion arose as to when and if section 47 safeguarding procedures applied and what the role of the social worker was in ensuring the welfare of a child identified as at risk of grooming and CSE. As we have previously argued (Kwhali et al., 2014) the separation of CSA from CSE may prevent sexually exploited children from receiving more individualised intervention expected through section 17 assessments and increases the risk of policy and practice silos (Brown et al., 2016).

Munro (2011) similarly identified how LAs were struggling under immense pressure to staff and resource an effective, child-centred child protection service and to respond robustly to existing and newly emerging forms of abuse. The 'cherry picking' of Munro's recommendations with a focus on structural change is unfortunate given the strong emphasis she placed on social work practice and understanding what she described as the child's journey through the child protection system. Social workers and managers in the research spoke consistently of the need for well-resourced, well-supervised and well-trained social workers and the valued contribution this would make in supporting sexually abused children and young people. We draw out these issues in the section that follows. 


\section{Main findings: effective support, supervision and training}

Social workers in the research talked at length about the complexity of their role and of the multifaceted issues that informed their work with sexually abused children. In addition to the knowledge and skills required to manage the investigative process, social workers spoke about the importance of being able to assess risk and understand the different forms of sexual abuse and their impact on children. Social workers required skills in direct practice with children and non-abusing family members, reflective and analytical skills, emotional resilience and the capacities to advocate for children during multi-agency investigative processes. Whilst the training and educational needs of those working in the duty and assessment and child protection/children in need teams were most evident from the discussions, social workers in leaving care, fostering and adoption, family support and disability services required similar knowledge and skills. Participants commented on there being no standard route or timescale in which children disclose abuse and additionally residential and leaving care settings may be the places where grooming is a specific risk factor. All child-care workers, therefore, need to be alert to the signs of abuse and have skills in working with children and young people post disclosure. As one worker commented when allocated a seemingly straightforward case that quickly escalated to one of sexual abuse, 'that can be quite overwhelming if you're not prepared for that' (LA1, FG2).

Social workers regarded university as the seat of academic knowledge: the place where they learn the theory that underpins their future longterm practice, and where preparation for CSA/E work should begin. Whilst they recognised the limitations of qualifying training being able to cover all topics in depth, none of the participants considered preparation for either CSA or CSE work to be adequate. The more experienced social workers suggested that the best preparation for working with children prior to the degree is nursery, family centre and residential work. Communication skills and knowledge of child development are central to a child-centred approach (Ruch, 2014) and these are locations where it is critical to develop relationships, maintain boundaries and learn about children's competencies.

At the post-qualifying level, social workers did not necessarily have access to appropriate knowledge and training. Comments from LSCB Chairs indicated that boards had responsibility for coordinating multiagency training plans and these plans had to cover all forms of safeguarding and a hugely varied knowledge and skill base amongst staff. Managers across the six participating authorities said that they generally encouraged staff to access training courses but were frequently hampered by limited resources, staff shortages and variable training quality. 
In addition, the social workers did not always consider the courses relevant to the specifics of their role; they often had to learn on the job or through supervision and support from more experienced workers. Such support was greatly valued, although team managers also commented on their variable experience and the time pressures associated with the organisational aspects of their role. Against this background, social workers felt that they continued to strive to do the best they could; however, our research identified some large cracks in their armour, including: insufficient preparation for CSA/E work as part of their qualifying training; the absence of a strategic, outcomes-led approach to training; the prioritisation of procedural training at the expense of therapeutic training; a minimalist approach to inter-agency training; and the absence of some aspects of training (Martin et al., 2014). Participants called for further training on risk assessments, direct work, grooming, different forms of abuse, children's behaviours relating to CSA and the use of tools (LA1, FG2) - in summary, better preparation for front line work.

There were also concerns expressed by social workers regarding approaches to diversity in practice, which increased in relation to postqualifying training, where the issue was largely ignored. Participants spoke of children being referred to during training as a homogenous group, with little recognition of differing needs based on their ethnicity or religion, leaving social workers to manage diversity alone in the field. This was especially evident in the authorities that were ethnically diverse, those with limited numbers of black and minority ethnic group staff or where issues of grooming and exploitation featured.

Finally, social workers also identified a need for training regarding the healthy development of children, particularly their sexual development. They spoke of their work being overrun with images and knowledge of abused children whose development has been hindered but rarely were they exposed in any depth to the lives of children who are developing healthily.

\section{Discussion and implications of the findings: developing staff in pressurised organisational settings}

The 2004 Children Act replaced Directors of Social Services with a single post of Director of Children's Services covering education, children's social work and related activity. It also established LSCBs in place of Area Child Protection Committees (ACPCs), placing inter-agency strategic planning and oversight on a statutory footing. There is little evidence that these structural changes have enhanced the support and supervision of staff, improved outcomes for vulnerable children or, since their implementation, prevented the abuse of children and young people. 
Ofsted's (2015) report into Children's Social Care identified a singularly depressing picture, with increased numbers of children in need, declining budgets, growing numbers of children on child protection plans (for all types of abuse) and the highest number of children looked after since 1987. It reports on the high turnover of managers and difficulties in recruiting and retaining experienced social workers. Two-thirds of LSCBs were considered less than good and none was rated outstanding; most LAs 'were only starting to understand the extent to which CSE was happening in their area' (Ofsted, 2015, p. 6), with children in care going missing from children's homes, with limited information as to their whereabouts or the reasons for their absence. Against this backcloth, it is difficult to see how improved pre, post and internal education and training alone will resolve the complex and multifaceted challenges faced by children's social work services. This is not to negate the critical importance of equipping social workers with enhanced skills and knowledge, but it is to question an approach that focuses on the skill set of individual social workers whilst ignoring the multitude of issues identified in the Ofsted report and over which social workers and their managers have limited control.

Social work degrees are a partnership between universities and the agencies and LAs who provide potential placements. It is in those placements that a student's practice capabilities are nurtured and theory applied. If the quality of many children's services is as poor as the Ofsted report (2015) implies, then, regardless of the education students receive at university, practice experiences will be compromised. Participants in this research highlighted the variable quality of their practice experiences and of the learning and supervision which they received.

This makes the current UK government's enthusiasm for 'front line' social worker training all the more curious, announcing as it did the expansion of the scheme prior to the first evaluation report. Frontline is aimed at 'high achieving University leavers and career changers' (Frontline, 2016) privileging academic qualifications over prior child-care and life experience. This approach contrasts with our research participants who considered direct work with children in family centre or residential care settings to be good preparation for social work training. Frontline recruits undertake a five-week residential training programme, including completing the 'readiness to practise' requirement, and are then placed in child protection teams, qualifying as a social worker after one year. The purpose of Frontline is to prepare entrants solely for children's social work using a specific model of intervention.

The evaluation report (Maxwell et al., 2016) suggests that the Frontline participants are 'significantly younger, more likely to have parents who were graduates and are more likely to have attended independent schools than those on traditional Masters' courses'. In the first 
cohort, only 2 per cent of participants identified themselves as being black against 19 per cent on all university-based courses.

Whilst the evaluation of Frontline provides some positive findings, what it cannot do is determine whether changing the socio-economic background from which social workers are recruited will provide more effective protection for children. Social work is involved in complex issues of structural inequality, poverty, ethnic and religious diversity and human need, and the Frontline recruitment practices appear to be drawing from a less diverse demography than has historically been encouraged (CCETSW, 1991), and which Reardon (2010) suggests is a core principle in social work education. This may contribute to the evaluation report's finding that 'Despite enjoying high ratings for practice quality, the Frontline trainees' rating of their own confidence in their abilities was lower than their mainstream counterparts' (Maxwell et al., 2016, p. 12). As our research emanated from expressed concern regarding the confidence of social workers in the field of CSA/CSE, this finding is particularly unwelcome and potentially concerning, whilst recognising that self-evaluation of both practice quality and confidence is inevitably subjective.

Laming's (2003) comment in his inquiry report that children are equally as entitled to protection regardless of nationality, culture or faith appears to have been interpreted as a green light for a colour-blind approach that ignores the relevance and complexity of such factors on family life, child upbringing and social work intervention. Participants considered themselves ill-equipped for the increasingly diverse context of their practice. Westwood (2012) suggests that culturally aligned practice is being forfeited in the realm of risk assessment. Recruitment practices, training models, values and ideas as to who is most suitable for social work training cannot sit apart from the demography of the children and families with whom social work is involved.

Once social workers have entered the post-qualifying arena, there are equally challenging issues in relation to maintaining and developing their expertise. The boundary between pre- and post-qualifying education and training is a moot point. The Assessed and Supported Year in Employment (ASYE) has helped to smooth the transition between the two (Berry-Lound and Rowe, 2013; McGregor, 2013) but the extent to which the social work qualification itself should prepare students to work in the more complex fields of child protection and CSA is an important debate.

Over time, most children's services departments have outsourced their training and, while their safeguarding training plans may appear to have a strategic drive, the focus of this is diluted or even lost by the time it trickles to social workers. While social workers in this research praised the quality of some of the training they received, the routes to accessing it lacked direction and there appeared to be no evaluation of the impact 
of training on their work-a concern also expressed in other research (Charles and Horwarth, 2009).

Of equal concern is the apparent relegation of inter-agency training. Problems with inter-agency working are well documented but its importance has risen over the last two decades, as it has been accepted as an effective vehicle for breaking down the barriers that transcend good practice (Glennie, 2007). Although its purpose is clearly stated by the UK government (Department for Education and Skills, 2006) and standards for such training were outlined over ten years ago (Shardlow et al., 2004), few social workers involved in this research recalled experiencing inter-agency training and, when they did, it was usually provided by the police, reinforcing the police's perceived lead role in safeguarding children.

This need should be considered alongside other comments from social workers who took part in this study that training is too procedural and therapeutic training is needed. At a time when social work literature is highlighting the importance of relationship-based social work and encouraging resistance to the ever-increasing task-focused, time-bound approach to intervention (Ferguson and Gates, 2015; Mason, 2012; Murphy et al., 2013; Ruch et al., 2010), social workers are echoing this message.

The suggestion from participants of the need to understand 'normal' sexual behaviour and child development is important if their practice is not to be viewed only through the prism of abnormality. It is a reality of social work training that it primarily focuses on the problems children and families experience without necessarily providing a comparator, but only if social workers are knowledgeable about sexual development can they confidently recognise those children for whom they need to be concerned-a point also alluded to in government guidance on the knowledge and skills required in child and family social work.

\section{Concluding remarks}

$\mathrm{CSA} / \mathrm{E}$ amongst children and young people is a substantive issue facing contemporary social work in the UK. Research addressing this issue is still an under-developed field and, where research is taking place, it is not necessarily permeating social work practice. CSA/E manifests itself in varied and increasingly complex forms and cannot be disentangled from family support and child protection issues more generally. Social workers clearly recognise the interrelationship between different forms of abuse and that CSA/E is also linked to issues of neglect and emotional well-being; they have a vital role in safeguarding vulnerable children and working with them and non-abusing family members in securing protection and support. This research highlights that, although 
social workers undertake this important work with a strong sense of commitment and concern for children, they face a number of challenges. Paradoxically, whilst their work on these cases is the source of intense scrutiny, the training, managerial and peer support, agency communication and role clarity required to undertake this work well is often overlooked.

The picture emerging from our research is that social workers face a constant undermining of their role from a range of directions. Continuous government reforms which ignore important messages from Munro (2011) and Croisdale-Appleby (2014) and threaten to redefine social work as little more than child-care regulation are chipping away at the confidence and morale of social workers. The focus of government and Chief Social Worker interventions appear to suggest that there is something inherently problematic about social workers themselves that can be improved if they are more tightly regulated, trained outside of universities or subject to post-qualification exams. The research suggests that social workers are highly motivated in their work with vulnerable children and often practise in the most challenging of circumstances. What many essentially lack is the resources to do the job and access to early intervention and therapeutic services that will support abused children. Social workers recognised the multiple needs of children and were frequently conflicted when they were unable to offer the time or resources that were required. The call for smaller caseloads, more time for direct practice, enhanced professional status, less paper work and reduced regulation and managerial direction merely echoes reports of the last decade.

As safeguarding tragedies continue to pervade the climate of social work at regular intervals, working within a culture of caution has become second nature. On a day-to-day basis, social workers and their managers work effectively together but the reality of the potential farreaching consequences of an oversight fuel an approach to work allocation and role delineation which can be confusing to social workers and which erodes their confidence in their professional ability. This in turn can impede social worker's effectiveness when working interprofessionally. The dominant role assumed by the police in cases of CSE is difficult to challenge without a strong professional identity and sense of self-worth that recognises the true value of the social work contribution. The lack of understanding that social workers believe other professionals have of their role is compromising and can only serve to belittle the complexity of their intervention. The steer for inter-professional working should come from the LSCB, but too often social workers are disconnected from this forum. Training plans need to reflect the needs identified by social workers rather than provide a managerial response to training that ensures social workers understand processes and policies but are not necessarily developing their skills in working or 
communicating with children. In addition, researchers in this field tread a fine ethical line when capturing how children's social work evolves in practice; hearing about excessively large caseloads, visits outside of working hours, closing of cases due to pressure of work and lack of response to children's needs from other agencies are all issues which raise concerns yet are not unfamiliar across a service that is experiencing unprecedented pressure.

In spite of the enormity of the challenges facing children's services, there are changes within their sphere of influence that this research supports. Training plans should be supported by an operational plan with a greater emphasis on impact evaluation; a more active dialogue between social workers and LSCBs might lead to training resources being targeted more effectively and the development of courses responding to identified need; issues of diversity must be integral to training provision; and a stronger push for multi-professional training may help social workers to transcend the barriers that threaten their ability to work confidently with the police and medical staff.

In the wider field of safeguarding children, good relationships, communication and strong collaborative leadership at all levels are critical to managing the mosaic of agencies involved and their overlapping roles. There are suggestions from this research that some relationships are fluid and/or fragile and there is clearly still work to be done in ensuring that agencies share an understanding of how to determine and meet the best interests of a child at every stage of intervention. Meeting this challenge is central to safeguarding practice and, whilst children's services cannot address it alone, they can and should take the lead.

\section{Acknowledgements}

We are grateful to the NSPCC who funded this research and to the professionals who gave their time to participate in focus groups and interviews.

\section{References}

Allnock, D., Radford, L., Bunting, L., Price, A., Morgan-Klein, N., Ellis, J. and Stafford, A. (2012) 'In demand: Therapeutic services for children and young people who have experienced sexual abuse', Child Abuse Review, 21, pp. 318-34.

Back, C., Gustafsson, P. A., Larsson, I. and Bertero, C. (2011) 'Managing the legal proceedings: An interpretative phenomenological analysis of sexually abused children's experience with the legal process', Child Abuse \& Neglect, 35, pp. 50-7.

Beckett, C. (2007) Child Protection: An Introduction, London, Sage.

Beckett, H. and Warrington, C. (2015) Making Justice Work: Experiences of Criminal Justice for Children and Young People Affected by Sexual Exploitation as Victims and Witnesses, Luton, Bedfordshire, University of Bedfordshire. 
Berry-Lound, D. and Rowe, V. (2013) Evaluation of the Implementation of the Assessed and Supported Year in Employment (the ASYE) for Skills for Care, Horsham, HOST Policy Research.

Brown, J., O’Donnell, T. and Erooga, M. (2011) Sexual Abuse: A Public Health Challenge, London, NSPCC, available online at www.nspcc.org.uk/inform/resour cesforprofessionals/sexualabuse/evidence-review-pdf_wdf87818.pdf.

Brown, S., Brady, G., Franklin, A., Bradley, L., Kerrigan, N. and Sealey, C. (2016) Child Sexual Abuse and Exploitation: Understanding Risk and Vulnerability, London, Early Intervention Foundation/Home Office.

Butler-Sloss, E. (1988) Report of the Inquiry into Child Abuse in Cleveland 1987, London, Her Majesty's Stationery Office.

Carpenter, J. and Hackett, S. (2016) Letting the Future In, London, NSPCC.

Central Council for Training and Education in Social Work (CCETSW) (1991) One Small Step towards Racial Justice, CCETSW.

Centre of Excellence for Information Sharing (2014) 'Information sharing: Understanding its role in the development of Multi-Agency Safeguarding Hubs', available online at http://informationsharing.org.uk/wp-content/uploads/2015/09/ P0316-MASH-findings-report.pdf.

Charles, M. and Howarth, J. (2009) 'Investing in interagency training to safeguard children: An act of faith or an act of reason?', Children and Society, 23(5), pp. 364-76.

Chilvers, A. (2013) 'Looking inside multi-agency safeguarding hubs', Journal of Family Health Care, Advance Access published March 6, 2016.

Crockett, R., Gilchrist, G., Davies, J., Henshall, A., Hoggart, L., Chandler, V., Sims, D. and Webb, J. (2013) Assessing the Early Impact of Multi Agency Safeguarding Hubs (MASH) in London, London, London Safeguarding Children's Board.

Croisdale-Appleby, D. (2014) Revisioning Social Work Education: An Independent Review, London, David Croisdale-Appley.

Department for Education and Home Office (2016) 'Statutory definition of child sexual exploitation', available online at www.gov.uk.

Department for Education and Skills (2006) Working Together to Safeguard Children: A Guide to Inter-Agency Working to Safeguard and Promote the Welfare of Children, London, The Stationery Office.

Department of Children, Schools and Families (2009) Safeguarding Children and Young People from Sexual Exploitation, London, HMSO.

Department of Health (2002) Safeguarding Children: A Joint Chief Inspectors Report on Arrangements to Safeguard Children, London, Gov. UK

Featherstone, B., Morris, K. and White, S. (2013) 'A marriage made in hell: Early intervention meets child protection', British Journal of Social Work, 44(7), pp. 1735-49.

Ferguson, H. (2011) Child Protection Practice, London, Palgrave Macmillan.

Ferguson, H. and Gates, P. (2015) 'Early intervention and holistic, relationship-based practice with fathers: evidence from the work of the Family Nurse Partnership', Child and Family Social Work, 20, pp. 96-105.

Fine, M. and Teram, E. (2013) 'Overt and covert ways of responding to moral injustices in social work practice: Heroes and mild-mannered social work bipeds', British Journal of Social Work, 43(7), pp. 1312-29. 
Frontline (2016) 'Frontline Summer Institute Programme', available online at www. thefrontline.org.uk/our-programme/frontline-programme-details/summer-institute 29/03/16.

Garrett, P. M. (2004) 'Talking child protection: The police and social workers "working together"”, Journal of Social Work, 4(1), pp. 77-97.

Glennie, S. (2007) 'Developing interprofessional relationships: Tapping the potential of inter-agency training', Child Abuse Review, 16, pp. 171-83.

HM Government (2015) Working Together to Safeguard Children: A Guide to InterAgency Working to Safeguard and Promote the Welfare of Children, available online at https://www.gov.uk/government/uploads/system/uploads/attachment_data/ file/419595/Working_Together_to_Safeguard_Children.pdf.

Home Office (2014) Working Together to Safeguard Children: Multi-Agency Safeguarding Hubs, London, Home Office.

Horvath, M. A. H., Davidson, J. C., Grove-Hills, J., Gekoski, A. and Choak, C. (2014) 'It's a Lonely Journey': A Rapid Evidence Assessment on Intrafamilial Child Sexual Abuse, London, Office of the Children's Commissioner.

Hughes, L. and Owen, H. (eds) (2009) Good Practice in Safeguarding Children: Working effectively in Child Protection, London, Jessica Kingsley.

Jay, A. (2014) Independent Inquiry into Child Sexual Exploitation in Rotherham 1997-2013, available online at www.rotherham.gov.uk/downloads/file/1407/inde pendent_inquiry_cse_in_rotherham.

Katz, D. and Kahn, R. L. (1978) The Social Psychology of Organizations, 2nd edn, New York, John Wiley.

Laming, W. (2003) The Victoria Climbié Inquiry, London, HMSO.

Martin, L., Brady, G., Kwhali, J., Brown, S. J. and Matouskova, G. (2014) Social Workers' Knowledge and Confidence when Working with Cases of Child Sexual Abuse: What Are the Issues and Challenges? London, NSPCC.

Mason, C. (2012) 'Social work the "art of relationship": Parents' perspectives on an intensive family support projects', Child and Family Social Work, 17, pp. 368-77.

Maxwell, N., Scourfield, J., Le Zhang, M., de Villiers, T., Hadfield, M., Kinnersley, P., Metcalf, L., Pithouse, A. and Tayyaba, S. (2016) Independent Evaluation of the Frontline Pilot: Research Report, Cardiff, Cardiff University/Department of Education.

McGregor, K. (2013) 'Two-thirds of newly qualified social workers would recommend the assessed year, finds first evaluation', Community Care 6/12/13, available online at www.communitycare.co.uk/2013/12/06/two-thirds-newly-qualified-social-workersrecommend-assessed-year-finds-first-evaluation/.

Munro, E. (2011) The Munro Report of Child Protection, London, HMSO.

Murphy, D., Duggan, M. and Joseph, S. (2013) 'Relationship-based social work and its compatibility with the person-centred approach: Principled versus instrumental perspectives', British Journal of Social Work, 43, pp. 703-19.

NSPCC (2015) 5 Child Sex Offences Reported Every Hour, available online at https://www.nspcc.org.uk/fighting-for-childhood/news-opinion/child-sex-offences-ukrecord-rise/.

NSPCC (2016) 'What is sexual abuse', available online at https://www.nspcc.org.uk/ preventing-abuse/child-abuse-and-neglect/child-sexual-abuse/.

Ofsted (2015) Ofsted Social Care Annual Report, available online at www.gov.uk.

Reardon, C. (2010) 'Reflecting diversity', Social Work Today, 10(5), p. 32. 
Ritchie, J. and Lewis, J. (eds) (2003) Qualitative Research Practice: A Guide for Social Science Students and Researchers, London, Sage.

Ruch, G. (2014) "'Helping children is a human process": Researching the challenges social workers face in communicating with children', British Journal of Social Work, 44, pp. 2145-62.

Ruch, G., Turney, D. and Ward, A. (2010) Relationship-Based Social Work: Getting to the Heart of Practice, London, Jessica Kingsley Publications

Searle, R. H. and Patent, V. (2013) 'Recruitment, retention and role slumping in child protection: The evaluation of in-service training initiatives', British Journal of Social Work, 43, pp. 1111-29.

Shardlow, S., Davis, C., Johnson, M., Long, T., Murphy, M. and Race, D. (2004) Education and Training for Inter-Agency Working: New Standards, Manchester, Salford Centre for Social Work Research, University of Salford.

Westwood, J. L. (2012) 'Constructing risk and avoiding need: Findings from interviews with social workers and police officers involved in safeguarding work with migrant children', Child Abuse Review, 21, pp. 349-61. 